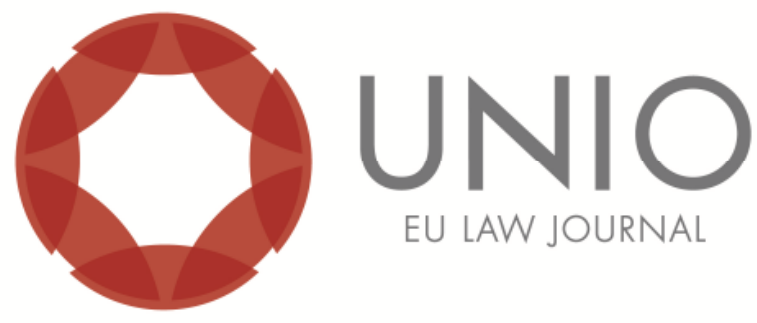

\title{
The Fuzzy Set Method in the Studies on the Multilevel Political System of the European Union
}

\author{
Janusz Ruszkowski*
}

\begin{abstract}
The political system of the European Union is unique and difficult to define. This presents significant problems to researchers attempting to clarify this phenomenon by means of conventional research methods. Thus, it seems necessary to start the search with other tools that will allow the exploration of the nature of this phenomenon. Such an unconventional instrument is the furay set method which has been used in logics, geometry and mathematics and which accumulates both a qualitative and a quantitative approach. When applied in the studies on the multi-level political system of the EU, it reveals phenomena that could not be seen when using conventional methods. One of the most important effects of this method exists in the furay levels of the EU political system situated among the traditional (crisp) levels (regional, national and supranational).
\end{abstract}

KEYWORDS: European Union - furay-set - multi-level governance - political system of the EU - supranationalism.

\footnotetext{
* Professor at the Institute of Political Science and European Studies of Szczecin University.
} 


\section{The fuzzy set method in European studies}

The fuzzy set ${ }^{1}$ method is a unique research tool stemming from mathematics, geometry and logics but which can be applied in the social sciences, hence in the European political studies. It combines the known quantitative and qualitative approaches and can be used in European studies to explain many phenomena that are hard to identify by means of traditional research methods.

Charles Ragin treats the fuzzy set method as a bridge between quantitative and qualitative methods and the scientific ideas (assumptions) and proofs. It links theory with data analysis. Researchers interested in qualitative analysis deal simultaneously with several cases, but their analysis remained oriented towards many aspects of the studied cases, and they explained the extent to which different elements of those cases are mutually related (contextually and historically). ${ }^{2}$

The fuzzy set method is based on the fuzzy set logic. ${ }^{3}$ Traditional dual logics (of two dimensions, sets or values), e.g. true or false, everything or nothing, and other examples fail to explain all the processes. Fuzzy set logic is an answer to these problems because it is the logics of three values or dimensions (or even the logics of more than three dimensions), e.g. true or false or an in-between state, black or white or grey situated between the former two.

The fuzzy set method helps to perceive states (objects, phenomena) that are situated inside conventional dichotomic sets (e.g. 'true' and 'false', 'yes' and 'no', 'black' and 'white'). Not frequently can we call things 'black' or 'white' and use extreme values. Therefore it should be emphasised that the fuzzy set method makes it possible to locate in-between conventional states (the 'grey areas') in two or more than two sets due to the application of a methodological solutions. As a result the method is used to explain more or less determined properties, states or features of a given event or phenomenon (object) being a part of a strongly non-homogenous (fuzzy) set or subset ${ }^{4}$ of events, objects or phenomena. Thanks to seizing fuzzy intervals, the fuzzy set method expands on a range of 'colours', shapes, impressions, states, aims, etc. and helps to choose the best of them (the ones that are the most appropriate in a given moment). ${ }^{5}$

A conventional set is dichotomic, which means that its given element can be

\footnotetext{
1 Fuzzy set appeared in 1965 as a mathematical method and theory introduced by Lotfi Zadeh, professor in the University of California, and since 1979 it has been dynamically developing as a method applied in such exact sciences as logics, mathematics or geometry. It has extended to all the existing methods analysing a shape of a given object (its distinct or fuzzy contour). See more about furzy set: Ch. Ragin, Furzy-Set Social Science, Chicago 2000, Ch. Ragin, The Comparative Method: Moving Beyond Qualitative and Quantitative Strategies, Berkeley 1987, Ch. Ragin, P. Pennings, Fuzzy Sets and Social Research, „Sociological Methods and Research”, 2005, Vol. 33, No. 4, Ch. Ragin, D. Berg-Schlosser, G. De Meur, Political Methodology: Qualitative Methods, in: R. E. Godin, H.-D. Klingemann (eds.), A New Handbook of Political Science, Oxford 1996, M. Koenig-Archibugi, Explaining Government Preferences for Institutional Change in EU Foreign and Security Policy, „International Organization”, January 2004, Vol. 58, No. 1, M. Koenig-Archibugi, Methodological Annex to "Explaining Government Preferences for Institutional Change in EU Foreign and Security Policy", London School of Economics and Political Science, July 2003, http://personal.lse.ac.uk/koenigar/Fuzzy-set\%20annex.pdf, J. Ruszkowski, Wstep do studiow europejskich. Zagadnienia teoretyczne i metodologiczne (Introduction to the European Studies. Theoretical and methodological Issues), Warszawa 2007.

2 See: Ch. C. Ragin, Furzy-Set Social Science, Chicago, London 2000, pp. XIV-XV.

3 It was Plato who created the foundations for furzy logics. He suggested the third dimension in between true and false that is a mixture of the two. Ch. C. Ragin has been trying an innovative application of the fuzzy set method to social sciences, but it was L. Zadeh who first applied it in the decision analysis, the control theory and in the expert systems in organizations.

4 Then we deal with the furay subset or fuzzy semiset methods.

${ }^{5}$ J. Ruszkowski, Wstep..., op. cit., p. 22.
} 
described by two ordinary states, i.e. it is either 'in' or 'out' of the set. For example, the conventional European set is comparable to a binary variable of two values: 'in' means (1) that he/she is a European, while 'out' means (0) that he/she is not a European. The fuzzy set method, however, permits membership in the intervals between 0 and 1, simultaneously preserving the two aforementioned conventional states, i.e. full membership in a set and full non-membership (absence) in another one. Thus a fuzzy set permits such types of membership as: units that are 'fully inside' (membership marked slightly more accurately as 1.0 ), 'almost inside' (0.90), the ones that are 'neither more inside nor more outside' (0.5), units that are 'slightly more outside than inside' (0.45) and, finally, the ones that are 'fully outside' (0) the set. The units between membership (1) and non-membership (0) are the units of fuzzy membership. In other words we can say that it is a partial membership. ${ }^{6}$ Therefore the fuzzy set method explains the contextual nature of phenomena and events.

In order to reduce a fuzzy set, that is to restore a conventional set (object) we use the defuzzyfication method with the aid of which we obtain clear values. Another defuzzification technique is centre of gravity which reduces a fuzzy set to its centre (or core). ${ }^{7}$

In European studies, the fuzzy set method can be used for example, to explain the process of instituting supranationality. According to Mathias Koenig-Archibugi supranationality can exist in two alternative combinations derived from two different analyses. The first fuzzy set approach says that supranationality is a combination of a regional government with political adjustment (the accordance and harmonisation). It can be presented as an equation:

regionalism + policy of harmonisation (adjustment) $=$ supranationalism.

According to the second analysis (the so called regressive analysis), supranationality is a combination of regionalism (regional regime) with the European identity as well as a smaller, more limited material capacity. ${ }^{8}$ Thus there are two routes leading to supranationalism: either a regional regime will be associated with harmonisation and accordance, which will be sufficient for supranationalism to occur, or the regional regime will be combined with a strong European identity and limited material capacity. 'Both combinations include the participation of a regional government thus, according to Koenig-Archibugi, its existence is so important that in such government's the absence of supranationalism cannot occur.

As it turns out, together with the development of European external affairs and the appearance of new actors in between the two traditional levels of international interactions (the logics of two dimensions) less popular subnational, transnational or supranational levels emerge (the logics of many dimensions). The supranationality in international relations and in European studies is another dimension (the furay set

\footnotetext{
${ }^{6}$ Charles Ragin sees at least four different states of membership (belonging to a set): a. those who are entirely outside the set (0), b. those who are not entirely outside the set, but still more 'out' than 'in' (fuz:y membership $>0$ but $<.5$ ), c. . those who are more 'in' than 'out', but still not entirely 'in' (furay membership $>.5$ but <1.0), d. those who are entirely inside the set (1.0). Ch. Ragin, Furay-Set Social Science, Chicago, London 2000, p. 7. J. Ruszkowski, Wstep..., op. cit., pp. 22-23.

7 Ibid., p. 23.

${ }^{8}$ M. Koenig-Archibugi, Explaining Government Preferences for Institutional Change in EU Foreign and Security Policy, „International Organization”, January 2004, Vol. 58, No. 1, p. 153.

9 Improved material capacity and well-being of countries do not encourage supranational cooperation, or supranational altruism.
} 
logic is based on the logics of three or more than three dimensions) in between the national (state) and the international dimension. ${ }^{10}$

Not only does the fuzzy set method facilitate the explanation for the existence of new levels of international cooperation, including the supranational level, but it can also be used to expound on the dynamic rules in the studies of the multilevel political system of the EU.

In the EU political system we can see that various reasons (or their combinations) can lead to the same results. For example, different ways of adapting the EU requirements in the member states bring the same effect. Or, different methods or means of implementing a given EU directive result in the same expected final effect that the directive sets forth. Such manifold causality leading to the same result is called equifinality. ${ }^{11}$ Thus equifinality indicates that a certain cause affects a result depending on its interactions with other factors (causes), which triggers off a combination of causes. The term 'equifinality' can also be understood as a flexible adaptation system, hence equifinality contributes to the analysis of the supranational impact. ${ }^{12}$

In the studies of manifold causality, or heterogeneous causality, conventional statistical methods or a conventional comparative analysis are not particularly useful. Unconventional methods, on the other hand, are more helpful since they combine the power of quantitative and qualitative methods, which have been so far used separately thus bringing only partial results. Such unconventional methods of quantitative and qualitative synthesis applied in social sciences, and particularly in comparative political and European studies, include the above mentioned fuzzy set method and the Qualitative Comparative Analysis (QCA) method. ${ }^{13}$ Ch. C. Ragin

$\overline{10}$ See J. Ruszkowski, $W$ step..., op. cit.

11 The term equifinality was used by Ludwig von Bertalanfy in 1940 who defined it as a rule characteristic of open systems. According to this rule a system can achieve the same final states resulting from different initial conditions and by means of different methods. Also, in a situation when open systems tend to regulatory mechanisms in order to control their own activity, the number of cases of manifold causality (equifinality) can be reduced. L. von Bertalanfy, Der Organismus als physykalisches System betrachtet, „Naturwissenschaften”, 1940, Nr. 28, p. 521. James Mahoney and Gary Goertz qualified equifinality to core concepts in qualitative research methods, although they both agree that it can be found in both qualitative and quantitative ones (it can combine both approaches, just as the fuzzy set method). J. Mahoney, G. Goertz, A Tale of Two Cultures: Contrasting Quantitative and Qualitative Research, „Political Analysis”, 2006, No. 14, p. 228.

12 We know that the supranational impact is strongest when the real costs of various operations (problem solving, regulations, agreements, activities, contract executions, etc.) in different institutional policies of the EU, as well as the projected costs, are equally high, often too high for some nationals or international players attempting to collaborate. What is more, that impact depends also on the level of capacity represented by a supranational institution to influence the results of agreements among governments and to encourage regional (supranational) or even to form desired transnational coalitions and to use them to implement initiatives that a given supranational institution comes out with. Such dependencies can be seen mainly in the EU cohesion policy, or in related support programs, whose subnational actors the European Commission successfully recruits and collaborates with. Similar dependencies can be found in the case of the European Groupings of Territorial Cooperation (EGTCs).

13 The QCA is an algebraic tool (applied mostly in Bool's algebra) adapted to political science needs by Charles C. Ragin. In situations when certain number of events in the international relations can be averaged and different events generate the same results, it is worth remembering that the impact that one factor has on these results depends on its interactions with other factors. Hence an appropriate combination of the analysed events makes it possible to compare the scale (quality) of the results they generate. The QCA uses the properties of equifinality and its use includes the studies of international alliances, forced diplomacy, revolutionary movements, the collapse of democratic governments, etc. See more: Ch. C. Ragin, Fuzzy-Set Social Science, Chicago, London 2000 and F. Laursen, S. Vanhoonacker, eds., Intergovernmental Conference on Political Union: Institutional Reforms, New Policies, and International Identity of the European Community, Dordrecht 1992. 
was the first to combine both methods into one fur:y set Qualitative Comparative Analysis $(f s / Q C A)^{14}$ which, contrary to the original QCA, is not only limited to the situations where the result and reasons for a given event or phenomenon to occur are either present or absent, but is also used to observe the third, intermediate states (that is why Ch. C. Ragin integrated both methods) and includes the probability of chance interpretation and takes the importance of statistics into consideration. Thus the $f s /$ QCA is a combination of quantitative and qualitative elements and is the extension of the basic methods that it consists of.

So, let us attempt to use the fuzzy set method to study the EU political system which is based on Multi-level Governance (MLG).

\section{The Extended Version of the EU Multi-level Governance (MLG)}

Classic Multi-level Governance (MLG) means that the EU political system ${ }^{15}$ is founded on a combination of supranational and intergovernmental organisations and on a certain degree of centralisation and decentralisation. The lowest level consists of regions and cities followed by nation states that, in turn, are overseen by supranational organisations. There is no centre of cumulated governmental power. Competences are redistributed among different levels of governance. Thus in the so defined political system of the EU there are, at least, three levels of relationships: the regional, the national and the supranational, which can be referred toas conventional because their character is unambiguous and they are easy to define.

The changes in the common decision-making process that have been observed since the 1980s have resulted in a gradually emerging multi-level political system (Multi-level Polity) which itself created numerous openings that made it accessible for various interest groups . ${ }^{16}$ This governance system, referred to as Multi-level Governance $(\mathrm{MLG})^{17}$, is not a stable equilibrium. It is rather a result of the allocation

\footnotetext{
${ }^{14}$ Ch. C. Ragin, Furzy-Set Social Science, Chicago, London 2000, p. 120-121.

15 According to James Caporaso before the early system in the European Union was founded (protoEuropean polity) Europe experienced disintegration of the Balance of Power system which had been coordinated by a network of bilateral and multilateral agreements among national governments. The process of forming the political system of EC/EU was accompanied by the establishment of independent political institutions operating on the supranational level. J. Caporaso, The Three Worlds of Regional Integration Theory in: Europeanization: New Research Agenda, eds. P. Graziano, M.P. Vink, Palgrave 2007, p. 24.

16 L. Hooghe, G. Marks, Multi-level Governance and European Integration, Lanham 2001, p. 28. More about research on EU MLG see: B.Kohler-Koch, F. Larat (Ed.), European Multi-Level Governance. Contrasting Images in National Research, Cheltenham, Northampton 2009, p. xix.

${ }^{17}$ The political system of the EU understood as Multi-level Governance where governments of member states are international actors along with subnational and supranational ones and which is opposite to other systems focused around the state (state-centric) was discussed by such authors as G. Marks, L. Hooghe and K. Blank. G. Marks, L. Hooghe, K. Blank, European Integration from the 1980s: State-Centric v. Multi-Level Governance, „Journal of Common Market Studies”, Vol. 34, 1996, p. 95-97 and further. Also in a modern theory of international relations more and more attention is paid to a discussion about Multi-level Governance in the world politics (see e.g. Global Governance), and not only in the international cooperation of regions. B. Kohler-Koch replaces the term of the Multi-level Governance by the penetrated governance (governance that penetrates several levels of integration). P. Craig, G. de Burca, EU Law. Text, Cases, and Materials, Oxford 2003, p. 6. We can call the MLG a kind of international regime, and more specifically - a multi-level regime. Markus Jachtenfuchs, in turn, introduces the term of the polycentric system of non-territorial based governance. M. Jachtenfuchs, Theoretical Perspectives on European Governance, „European Law Journal”, 1995, No. 1, 2, p. 125. In the reference
} 
of competences among national and supranational actors. The Council of the European Union, the European Commission and the European Parliament ${ }^{18}$ interact with each other under the European legal order which, through the innovative jurisdiction of the European Court of Justice, has been transformed in order to establish the supranational order.

G. Marks defines Multi-level Governance as a system of permanent negotiations run by governments on several territorial levels - the supranational, the national, the regional and the local level - as a result of a broader process of establishing institutions and restructuring the decision-making systems. This process is based on delegating some centralised competences of individual states 'upwards' to supranational organisations, or 'downwards' to the regional or local level. ${ }^{19}$ Therefore the decision-making process in a multi-level structure moves away from a national government in two directions: 'upwards' to supranational organisations ${ }^{20}$ and 'downwards' to subnational units. ${ }^{21}$

G. Marks and L. Hooghe mention two types of power-sharing in the MLG of the European Union. The first one refers to the hierarchic sharing of power among different levels (which is limited) where the competence and the powers to act are well defined, just as in a federation. In the second type, governance is constituted by fragmented but functional and specialised institutions, which have 'blurred' borders as they overlap each other, while executing their unique responsibilities. The number of levels among which functions are to be distributed is unlimited. Furthermore Marks and Hooghe claim that the European Union is an exception where the first type of power-sharing is observed, because it exists within individual member-states. ${ }^{22}$ Thus a problem would arise if the number of levels in the EU were to be limited to the afore-mentioned traditional (conventional) levels.

literature we can find such definitions of the EU political system as: polycratic governance (C. Landfried, The European Regulation of Biotechnology by Polycratic Governance, in: Ch. Joerges, E. Vos, eds., EU Committees: Social Regulation, Law and Politics, Oxford 1999, p. 173.), network governance (B. KohlerKoch, The Evolution and Transformation of European Governance, in: B. Kohler Koch, E. Eising, eds., The Transforming of Governance in the European Union, London, New York 1999, p. 15.). See also a broader term European Polyphony in: O. Weaver et. al. (ed.), European Polyphony. Perspectives Beyond East-West Confrontation, London 1989.

18 The EU institutions operate similarly to international regimes.

${ }^{19}$ G. Marks, Structural Policy in the European Community, in: A. M. Sbragia (ed.), Europolitics: Institutions and Policy-Making in the New European Community, Washington, 1992, p. 211.

20 Political centralisation is a long-lasting trend that can be noticed in all the multi-level political systems. As a rule, political systems are barely centralised at their onset. However, as they are growing and evolving, the degree of centralisation is rising as competences are gradually delegated to central agents who cumulate their prerogatives and manage them centrally, e.g. supranationally.

${ }^{21}$ Governance in the EU can be executed beyond a national state (mainly on the supranational level) although on other levels and in inter-level combinations it takes place with the participation of member states falling under typical for the Governance institutionalization. Thus it is possible to ignore a state in the process of power-sharing or decision-making because both the above mentioned can occur between the supranational Community institutions and subnational authorities (regional, subfederal, etc.). We cannot forget that the state can maintain certain elements of control and influence on those processes through the EU institutions of inter-governmental character (the Council of the European Union, the European Council - where member states play their leading role through their governments).

${ }^{22}$ G. Marks, L. Hooghe, Contrasting Visions of Multi-level Governance in: I. Bache, M. Flinders (eds.), Multi-level Governance, Oxford 2004, pp. 22-23 and 28. According to the authors the second variation of power-sharing is more favourable for creating free trade areas and common markets. 
Thus the classic model of the EU political system as the Multi-level Governance (MLG) presents only the 'conventional' (unconditional) levels, i.e. the ones that are strictly defined by the players. For example, the actors operating on the regional (subnational) level belong to this level because they constitute the set of regional actors (regional or local governments, and other examples), the actors operating on the national level simultaneously belong to that level (e.g. national governments, states, national institutions, etc.). Finally, the actors operating on the supranational level are assigned to this level and they create the set of supranational actors (e.g. the EU institutions). ${ }^{23}$ This approach, however, does not consider the dependencies among the levels including the activities within the EU political system that are hard to be attributed to one of the known conventional levels.

The undisputable character of the traditional approach to the levels in the MLG stems from the clear logic of two dimensions, i.e. the presence or absence of actors in a given set (here on a given level). However, when we apply research methods based on the logic of more than two dimensions, e.g. the fuzzy set method, it becomes apparent that this method presumes not only the presence in a given set in its pure form (full membership inside), which in the fuzzy set terms is defined as ' 1 ', or the lack of presence (the lack of affiliation) in the set defined as ' 0 ', ${ }^{24}$ but, most importantly, such logic enables us to define the states in-between the sets, i.e. what is happening in the point of their crossover or in the situation when their membership is not 'complete' (full), but it is more 'inside' or more 'outside', etc. Thus the most significant are fuzzy spaces or crossover points (cps) ${ }^{25}$ of a given set or dimension. If we adopt, as a dimension in the EU, the level of management that is familiar to us (regional, national, supranational) with a defined set of affiliated actors, it happens to be the case that those actors are able to operate not only on their own level, but also on a different level or at a contact point with another level (in-between the levels) where they create a new, fuzzy operation level and use all the advantages of the other levels. According to B. Jones and M. Keating, an exemplary combination of the capacity of actors operating on the supranational (European) and the regional levels, especially the type of their activity, brings a new result of a diversified character which is a consequence of transferring activities in bilateral relations between central and local ${ }^{26}$, where local means a supranational level in the EU

23 The issue of set-theoretic relationship is of central importance in reference to the relation between theoretical argumentation and empirical analysis and that is why researchers dealing with social sciences should not ignore it.

${ }^{24}$ Furyy set embodies both qualitative states (full membership in the set [1.0] and full nonmembership in the set [0]) as well as the variations occurring on the in-between levels (i.e. between 0 and 1.0)in one instrument. Ch. Ragin, Fuzzy-Set... op. cit.,p. 9, Ch. Ragin, The Comparative Method...op. cit.,, Ch. Ragin, P. Pennings, Fuzzy Sets and Social Research... op. cit.,, J. Ruszkowski, Wstep..., op. cit., p. 22. Charles Ragin mentions at least four different memberships: 1 . those who are fully outside the set $(0), 2$. those who are not fully outside the set, but more 'out' than 'in' (fuzay membership $>0$ but $<.5)$, , 3. those who are more 'in' than 'out', but not fully 'in' (furzy membership $>.5$ but <1.0), 4. those who are fully inside the set (1.0). Ch. Ragin, Furzy-Set... op .cit., s. 7. J. Ruszkowski, Wstep...op. cit., pp. 22-23.

${ }^{25}$ A crossover point (.5) is a point of maximum ambiguity (more 'in' or more outside the set). (.5) is the main part of a furzy set.

${ }^{26}$ B. Jones, M. Keating (eds.), The European Union and the Region, Oxford 1995, p. 291. It also happens that due to the EU cohesion policy (before 2007 defined as a regional policy) strong regions 
and local a regional one.

We can assume that the opportunity to define the points of the set (level) crossover is specific evidence that proves that the fuzzy space exists within the conventional levels. Subsequently, incorporating this evidence to the direct analysis of the fuzzy levels within the MLG of the EU will facilitate the determination of the specific character of the new levels.

Let us check the results of applying the fuzzy set method to the analysis of the European Grouping of Territorial Cooperation $\left(\mathrm{EGTC}^{27}\right)$.

First we should define all the reasons in a form of hypotheses $(H)$, i.e. the necessary and sufficient conditions ${ }^{28}$ that can affect the establishment of the EGTC. At the same time we define the sets of actors of a particular membership. The sets will be considered in the further study (see the Breakdown 1). Then we select all the possible variations of the set and the membership combinations in order to find the points (or a point) of their crossover. The crossover points are a vital proof that the fuzzy space (a new fuzzy level) exists.

\section{Breakdown 1.}

\section{The fuzzy set analysis in reference to EGTC}

Reasons in a form of hypotheses $(H)$ that can affect the establishment of the EGTC:

$H 1$ : Being a region in the EU member state (set $A$ ) is a necessary condition for the EGTC to come to existence.

H2: Being a region belonging to the EGTC (set $B$ ) is a necessary condition to

strengthen their position in relation to the central government (which can be seen in federations such as Germany). According to L. Hooghe, the EU cohesion policy does not diminish the significance of the relations between subnational (regional) actors and the central government. That policy makes it even clearer that subnational actors (e.g. local governments) in federal countries are more efficient than local governments in less decentralised countries. L. Hooghe (ed.) Cohesion Policy and European Integration: Building Multi-Level Governance, Oxford 1996, p. 13.

27 The European Groupings of Territorial Cooperation are based on the Regulation (EC) No 1082/2006 of the European Parliament and of the Council of 5 July 2006 on a European grouping of territorial cooperation (EGTC), OJ L 210, 31.07.2006. The establishment of the EGTC was proposed by the Committee of the Regions. The EGTCs are a new form of cooperation invested with legal personality that are able to establish its statutes and equip themselves with its own organs, as well as rules for their budget. They may, in particular, acquire or dispose of movable and immovable property and employ staff. Until 2009 eight EGTCs have been established in the EU.

${ }^{28}$ In social science the strategy to study individual reasons is not a good solution because, as a rule, causality is complex, or manifold. We know, however, that different reasons can lead to the same results (equifinality). Determination of conditions (reasons) that are necessary or sufficient is a very important task in the initial phase of a study conducted by means of the fuzzy set method. As far as a necessary condition is concerned meeting its requirements (the occurrence of a necessary reason) is necessary but not sufficient for a result to occur. It means that meeting a necessary condition will not make the result happen. In the case of a sufficient condition (the occurrence of a sufficient reason) meeting it is sufficient but not necessary for a result to occur. It means that even if a sufficient condition does not occur, a result will happen anyway. In other words, a condition (reason) that is sufficient is enough for a result to occur, regardless of other reasons being present or absent. Hence the analysis of necessary and sufficient causality is of key importance in the fuzzy set method and the QCA. See: Ch. Ragin, Furzy-Set Social Science, Chicago 2000, M. Koenig-Archibugi, Methodological Annex to "Explaining Government Preferences for Institutional Change in EU Foreign and Security Policy", London School of Economics and Political Science, July 2003, http://personal.lse.ac.uk/koenigar/ Fuzzy-set\%20annex.pdf, pp.2-3 and M. Koenig-Archibugi, Explaining Government Preferences for Institutional Change in EU Foreign and Security Policy, „International Organization”, January 2004, Vol. 58, No. 1. 
adopt supranational rules. ${ }^{29}$

H3: Being a region of a EU member state and belonging to the EGTC is a sufficient condition to adopt supranational rules.

H4: Being a EU member state (set $C$ ) is a necessary condition for the EGTC to come to existence.

H5: Being a EU member state that at the same time belongs to the EGTC (set $D$ ) together with the regions belonging to the EGTC (set B) is a sufficient condition to adopt supranational rules.

Thus there are four sets including a specific membership:

Set $A$ : regions in the EU member states (on the regional level)

Set $B$ : regions belonging the EGTC (on the supranational level)

Set $C$ : the EU member states (on the national level)

Set $D \& B$ : the states belonging to the EGTC together with the regions (on the supranational level)

Therefore for the EGTC to emerge we need two variations of the set combination (crossover) ${ }^{30}$ that guarantee the new results to appear:

$A^{*} B$

$C^{*}\left(D^{*} \mathrm{~B}\right)$

(where , ${ }^{*}$ " is the conjunction ,and" ${ }^{31}$ )

If the region belongs both to the set $A$ (the regions in the EU member states) and to the set $B$ (the regions belonging to the supranational EGTC), it means that it is situated at the point of the crossover of these two sets: the regional $A$ and supranational $B$ ). So this region belongs to the fuzzy set of the regions adopting the supranational rules. It is the first crossover point $(c p)$ between the regional and supranational levels, i.e.:

$A^{*} B=c p 1$.

The new result of this particular combination is that the EGTCs operate on the regional-supranational fuzzy level. The 'constitutional culture' of the EGTC has become polycentric. ${ }^{32}$

So each EGTC operates at least on the regional-supranational fuzzy level. But any EGTC can be joined by a state. If such a state belongs both to the set $C$ (the EU member states) and to the set $D \& B$ (states and regions belonging to a EGTC), it means that it is situated at a junction of two sets - the national $C$ and the regional-supranational $D \& B$ ), thus this country belongs to the fuzzy set of the states and regions that have adopted supranational rules of the EGTC. It is another crossover point $(c p)$ between the national and regional-supranational levels, i.e.:

29 Common statute, legal personality, liability to the Community law, ability to employ staff and establish budget, etc.

30 On combination (crossover) of sets see also: M. Koenig-Archibugi, Methodological Annex to "Explaining Government Preferences for Institutional Change in EU Foreign and Security Policy", London School of Economics and Political Science, July 2003, http://personal.lse.ac.uk/koenigar/Fuzzyset\%20annex.pdf, pp.2-3 and M. Koenig-Archibugi, Explaining Government Preferences for Institutional Change in EU Foreign and Security Policy, „International Organization”, January 2004, Vol. 58, No. 1.

${ }^{31}$ Such designation can be found in Boole's algebra on which the QCA and QCA/furzy set methods are based.

32 J. Friedrichs, F. Kratochwil, On Acting and Knowing: How Pragmatism Can Advance International Relations Research and Methodology, „International Organization”, 2009, Vol. 63, No. 4, p. 722. 
$C^{*}\left(D^{*} B\right)=c p 2$.

The new result of such a combination is that the EGTCs operates on the regional- national-supranational fuzzy level.

Breakdown 1 contains a procedure of scientific argumentation based on the fuzzy set demonstrating that there are two crossover points between the sets that are necessary for an EGTC to be established. If EGTCs consist of regions only, they meet the condition of operating on the regional-supranational fuzzy level. On the other hand, EGTCs consisting of both states and regions meet the condition of operating on the regional-national-supranational fuzzy level.

Thanks to the fuzzy set method the factors which explain necessary and sufficient reasons for a certain event to occur work together in order to bring a new result - the EGTCs. It has already been mentioned that when various reasons lead to the same result, we deal with equifinality. The fuzzy set method helps to reveal manifold causality (equifinality) as well as such combinations of reasons that can crossover and expose the main part of the fuzzy set, i.e. the maximum ambiguity at the crossover points.

So it is apparent that the European Groupings of Territorial Cooperation are an interesting and new example of the regional-national-supranational fuzzy level. We have already learnt that they are carriers of rights and that they are a form of cooperation based on the powers delegated by local and regional authorities or other organisations from the EU member states. All that is aimed to establish this type of groupings being the first crossover point between the regional and supranational levels. The EGTCs are an innovative solution whose character is designed to reach a supranational degree but which are to operate on fuzzy levels and generate collaboration both of the regions in the EU member states or local and territorial governments and the member states themselves. The EGTCs are based in one selected EU state which can but do not have to be their member. Then they are managed according to the national law of the host country, as well as Community law (the second crossover point, this time between the national and regional-supranational levels). The EGTCs are an excellent example of a new result attributable to various factors and situated on a fuzzy level, with one or two crossover points, and spread between two or even three conventional levels: the regional, the national and the supranational ones. Thus the EGTCs play the role of a specific laboratory in the system multilevel governance in the EU. ${ }^{33}$

Our search for new fuzzy levels in the MLG by means of the fuzzy set method draws our attention to the effects of the activities within the EU political system that are undertaken with the use of shared powers, i.e. of such powers which in a given area (e.g. sectoral policies) belong simultaneously to the EU members states and to the supranational institutions (or to the European Union). We will present this analysis on the basis of international mixed agreements ${ }^{34}$ signed by both

\footnotetext{
33 J. Ruszkowski, Ponadnarodowosc w systemie politycznym Unii Europejskiej (Supranationalism in the political system of the European Union), Wolters Kluwer Waszawa 2010 .

34 See more: J. Sozański, Porozumienia miedzynarodowe W spolnot i Unii Europejskiej (International Agreements of the Comunities and European Union), Torun 2007.
} 
member states and the European Union. ${ }^{35}$

Where the external authority [of the Union] is not exclusive (...) the member states are not totally devoid of the right to act on the international arena, but their independence in this aspect is limited by the existence of the [Union's] authority. (...) In such a case mixed (external) agreements are executed. ${ }^{36}$ These agreements are of a mixed nature because their subject and material range is neither exclusively subject to the EU nor to the national authority, but is subject to both the shared powers of the Union and its member states. Therefore both negotiating such agreements and their subsequent execution requires close cooperation between the EU itself and its member states.

To start with we should define - just as in the case of the EGTCs - the reasons in a form of hypotheses (i.e. necessary conditions and sufficient conditions) that may influence the execution of international mixed agreements between the EU and its members. ${ }^{37}$ Then we should follow Breakdown 2.

\section{Breakdown 2.}

\section{The fuzzy set analysis in reference to international mixed agreements}

Reasons in a form of hypotheses $(H)$ that can affect the execution of international mixed agreements:

H1: Being an EU member state (set $A$ ) is a necessary condition to sign an international mixed agreement with a third country or with an international organisation

H2: Being in the European Union as a carrier of rights (set $B$ ) is a necessary condition to sign an international mixed agreement with a third country or with an international organisation

H3: Being third country or an international organisation (set $C$ ) is a sufficient condition to sign an international mixed agreement with the EC

H4: Being the EU member state (set A) with the European Union as a carrier of rights (set $B$ ) is a sufficient condition to sign an international mixed agreement with the third country or with an international organisation.

Thus there are three sets containing a particular membership:

Set $A$ : the EU member states (on the national level)

Set $B: \quad$ the European Union as a carrier of rights (on the supranational level)

Set $C$ : the third countries and international organisations

So in order to execute an international mixed agreement with the third countries or with international organisations we require one variation of the combination (crossover) of sets which will bring a new result:

$\left(A^{*} B\right)^{*} C$

(where '* ' is a conjunction 'and')

\footnotetext{
35 Since December 2009 such agreements can be executed by the European Union because it was given the status of an international legal personality by the Treaty of Lisbon (see Article 1 and 46a). Official Journal of the EU, C306, Vol. 50, 17.12.2007.

36 A. Grzelak, Mozliwosc ratyfikacji Konwencji w sprawie kontaktow z dziecmi w swietle stanowiska Federalnego Ministerstwa Sprawiedliwosci RFN, „Zeszyty Prawnicze”. Biuro Analiz Sejmowych. Kancelaria Sejmu, 2009, No 1 (21), p. 114.

${ }^{37}$ Such agreements are for example the agreement concerning the European Economic Area or the former Lomé conventions.
} 
If an EU member state (set A) forms a shared set with the European Union as a carrier of rights (set B), which is a necessary condition to sign an international mixed agreement with a third country or with an international organisation (set C), then the member state and the EU constitute a fuzzy set A and $\mathrm{B}$. It is a crossover point between the national and the supranational level, so $\left(A^{*} B\right)^{*} C=c p$.

The new result of such combination are international mixed agreements that illustrate the nature of the national-supranational fuzzy level.

Hence the international mixed agreements are created at the crossover point, i.e. on the national-supranational level because it is the European Community (the European Union since December 1, 2009) as an international carrier of rights along with the member states (and their national institutions) that have influence on the execution of such agreements. Therefore the new national-supranational level in the EU political system is a fuzzy level on which a defined activity brings new results.

As a result of the analysis carried out with the use of the fuzzy set method, apart from conventional levels of the EU political system, we can also see fuzzy levels, i.e. the ones where the activities and responsibilities of conventional levels overlap and where crossover points appear. The fuzzy levels are the new levels emerging either at the contact point of two conventional levels or when conventional (crisp) levels overlap due to crossover points.

Let us present two other examples of events that probably occur on the fuzzy levels in EU the multi-level political system (MLG), but let us restrict our presentation to results only and skip the process of proving according to the rules of the fuzzy set method since it is necessary to show how the method is useful. Here are two examples of results (activities) that are likely to occur on fuzzy levels:

1. The co-decision procedure (legislative procedure by which regulations are adopted together by the inter-governmental Council of the European Union representing the interests of nation countries and by the supranational European Parliament) is a form of governance in the European political system executed on the national-supranational level because the legal act that has been adopted in this way results from the activity taking place at the crossover point between the national and the supranational levels.

2. The Representation Offices of the regions to the European Union opened in Brussels are a means of identifying these institutions on a regional-subnational fuzzy level (with the omission of the member states).

The lack of the fuzzy set analysis of the above mentioned examples (in a form of results rather than proofs) that are likely to occur on the fuzzy levels of the MLG in the European Union shows how important the fuzzy set method is. In fact, it can be used to support arguments that we are dealing with in combination of sets (in the point of their crossover or contact) and with its new final result located on a fuzzy level.

Graph1 presents the location of fuzzy levels among the conventional ones.

\section{Graph 1.}

Complex system of multi-level governance in the EU 
CONVENTIONAL LEVELS

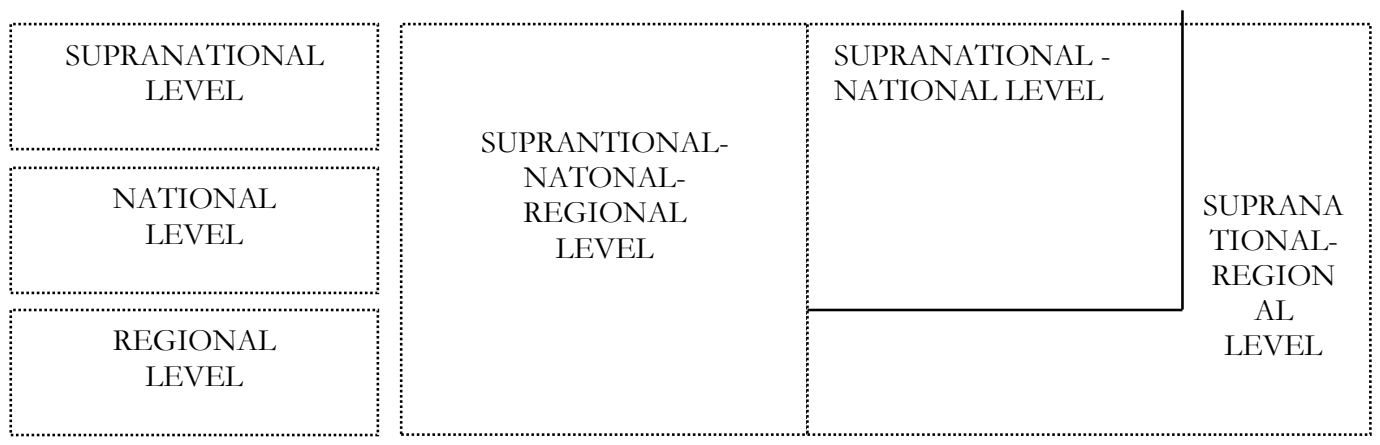

Fuzzy levels demonstrate the type of activity in the multi-level political system of the EU which have been hard to define in the political sciences thus far. They have also been difficult to locate and name. Therefore, in order to explain the nature of this activity and to overcome the above problems, a more serviceable tool should be applied, and that tool is the fuzzy set method. It certainly offers new opportunities and opens new areas in European studies.

\section{Conclusion}

Courtesy of the fuzzy set method at least three new fuzzy levels in the multilevel political system of the EU have been identified in this study: 1. the nationalsupranational level, 2. the regional-supranational level, and 3. the regional-nationalsupranational level. We should naturally assume, that further research into this field will extend the area of study and support the thesis that the number of levels in the MLG is not limited to the known conventional (crisp) ones.

So the political system of the EU is a system of multi-level governance executed on conventional and fuzzy levels, as well as in-between these levels, consequently, the MLG is a conglomeration of all of the aforementioned levels. 